\title{
INFRAESTRUCTURA NATURAL PARA RECUPERACIÓN DE SERVICIOS ECOSISTÉMICOS CON FINES DE MITIGACIÓN DE RIESGOS DE INUNDACIÓN Y MOVIMIENTOS DE MASA
}

\author{
NATURAL INFRASTRUCTURE FOR RECOVERING ECOSYSTEM SERVICES FOR FLOOD RISK MITIGATION AND \\ MASS MOVEMENT PURPOSES
}

https://doi.org/10.52109/cyp2021110

Gustavo Dongo ${ }^{1}$

${ }^{1}$ Investigador independiente

\section{REGISTROS}

Recibido el 15/08/2020

Aceptado el 30/09/2020

Publicado el 31/01/2021

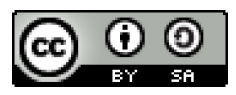

\section{PALABRAS CLAVE}

Mitigación de riesgos, movimientos de masa, plantaciones forestales, manejo de pastos, erosión.

\section{KEYWORDS}

Mitigation of risks, mass movements, forest plantations, pasture management, erosion.

\section{RESUMEN}

El objetivo general del estudio es determinar las acciones que involucren infraestructura natural y las áreas aptas con fines de mitigación de riesgos de inundación y movimientos de masa en la cuenca del Río Rímac. Se evaluaron los factores que influyen de manera directa en la determinación de intervenciones y áreas óptimas con fines de mitigación de riesgos de inundación y movimientos de masa en cuencas hidrológicas mediante Técnicas de Evaluación Multicriterio y Sistemas de Información Geográfica (SIG), trabajo de campo, consultas a pobladores y autoridades de las Comunidades Campesinas del ámbito de la cuenca. Con la información obtenida mediante el Modelo de Capacidad de Acogida y utilizando información oficial y de WorldClim - GlobalClimate Data; se construyó una base de datos digital vectorial que incluyó altitud, pendientes, cobertura vegetal, precipitación, vigor de la vegetación, vías, riesgos geológicos, susceptibilidad a movimientos de masa, áreas agrícolas, áreas potenciales para plantaciones. El mapa resultante muestra las superficies aptas para intervenciones de infraestructura natural con fines de mitigación de riesgos de inundaciones y movimientos de masa en la cuenca Rímac. 


\section{INTRODUCCIÓN}

En la Constitución Política del Perú el artículo 68 de dicha norma señala que «El Estado está obligado a promover la conservación de la diversidad biológica y de las áreas naturales protegidas»

En el segundo párrafo del literal b del artículo 3 de la Ley 30215, se afirma que «el Estado es responsable de promover la inversión pública y privada en la conservación, recuperación y uso sostenible de las fuentes de los servicios ecosistémicos.

Se recomienda la formulación de estudios para Plantaciones Forestales con fines productivos y asimismo formulación de Proyectos Forestales con Fines de Servicios Ambientales Prioritarios: Regulación Hídrica, Control de Erosión de Suelos; de acuerdo a la Resolución Directoral n. ${ }^{\circ}$ 006-2015-EF/63.01, publicada el 13 de agosto 2015, en concordancia con los Lineamientos de Política de Inversión Público en materia Diversidad Biológica y Servicios Ecosistémicos 2015-2021, aprobado con Resolución Ministerial n.ำ199- 2015- MINAM.

Debido a la dificultad de intervenciones en un área extensa y heterogénea como es la cuenca del río Rímac, se necesita de herramientas que puedan facilitar y optimizar los recursos como son las técnicas cartográficas y de teledetección, que permiten desarrollar procesos de análisis, planificación, gestión y control de los recursos físicos ambientales y socioculturales.

\section{Definiciones y consideraciones básicas}

\section{Ecosistema}

Complejo dinámico de comunidades vegetales, animales y de microorganismos y su medio no viviente que interactúan como unidad funcional. En la Tabla 1.1 se listan los tipos de ecosistemas existentes en el país.

Tabla 1

Tipos de ecosistemas en la cuenca Rímac

\begin{tabular}{ll}
\hline Región Natural & \\
\hline & Ecosistema \\
& - Manglar ${ }^{*}$ ) \\
& - Bosque estacionalmente seco de colina y montaña \\
Costa & - Loma costera \\
& - Matorral xérico \\
& - Bosque estacionalmente seco de llanura \\
& - Bosque estacionalmente seco ribereño (algarrobal) \\
& - Desierto costero
\end{tabular}




\begin{tabular}{|c|c|}
\hline Región Natural & Ecosistema \\
\hline \multirow{13}{*}{ Andina } & - Humedal costero \\
\hline & - Páramo \\
\hline & - Pajonal de Puna seca \\
\hline & - Pajonal de Puna húmeda \\
\hline & - $\quad$ Bofedal $(*)$ \\
\hline & - Zona periglaciar y glaciar \\
\hline & - Jalca \\
\hline & - Matorral de Puna Seca \\
\hline & - Bosque relicto altoandino (queñoal y otros) \\
\hline & - Bosque relicto montano de vertiente occidental \\
\hline & - Bosque relicto mesoandino \\
\hline & $\begin{array}{l}\text { - Bosque estacionalmente seco interandino (Marañón, } \\
\text { Mantaro, Pampas y Apurímac) }\end{array}$ \\
\hline & - Matorral andino \\
\hline \multirow{4}{*}{ Yunga } & - Bosque basimontano de yunga \\
\hline & - Bosque montano de yunga \\
\hline & - Bosque altimontano (pluvial) de yunga \\
\hline & - Matorral montano \\
\hline $\begin{array}{l}\text { Ecosistemas } \\
\text { acuáticos }\end{array}$ & - Lagos y lagunas \\
\hline
\end{tabular}

(*) Se refiere a humedales

Fuente: Definiciones conceptuales de los ecosistemas del Perú. MINAM $2018^{1}$

\section{Servicios ecosistémicos de regulación hídrica y control de erosión de suelos}

Los servicios ecosistémicos son aquellos beneficios económicos, sociales y ambientales, directos e indirectos, que las personas obtienen del buen funcionamiento de los ecosistemas y se agrupan en cuatro tipos: 1) de provisión, como alimentos, agua, materias primas; 2 ) de regulación, como regulación del clima, regulación hídrica, control de erosión de suelos, secuestro de carbono; 3) culturales, como belleza paisajista, recreación y ecoturismo; y, 4) de soporte, como formación de suelos, mantenimiento de la biodiversidad.

El servicio de regulación hídrica consiste en el almacenamiento de agua en los períodos lluviosos y la liberación en los periodos secos. El ecosistema proporciona un balance natural entre caudales en época lluviosa con caudales de estiaje. La regulación hídrica depende principalmente de la intensidad y la estacionalidad de las precipitaciones, la cobertura vegetal, la profundidad del suelo, la variabilidad climática y las prácticas de conservación de agua.

El servicio de control de erosión de suelos se refiere a la capacidad del ecosistema de disminuir las fuerzas que provocan el desprendimiento de las partículas de suelo,

${ }^{1}$ Aprobado mediante R.M N ${ }^{\circ}$ 440-2018-MINAM, publicada en el diario El Peruano el 21.12.2018. 
principalmente las fuerzas de erosión producidas por el agua. La cobertura vegetal evita la exposición del suelo a la acción de la lluvia, la escorrentía y el viento, impidiendo la erosión.

\section{Infraestructura natural}

Es la red de espacios naturales que conservan los valores y funciones de los ecosistemas, proveyendo servicios ecosistémicos. En la red de espacios naturales se incluyen el conjunto de ecosistemas recuperados y conservados, a través de intervenciones consideradas como inversiones o actividades.

\section{Infraestructura física}

Es el conjunto de estructuras de ingeniería e instalaciones que constituyen la base para la prestación de servicios necesarios para el desarrollo.

\section{Capital natural}

Es el stock de recursos naturales renovables y no renovables que se combinan para producir un flujo de beneficios o servicios para la sociedad. En el caso de los recursos naturales renovables, estos se forman a partir de la recuperación y conservación de la infraestructura natural.

\section{Activos}

\section{Unidad Productora}

En el Sistema de Programación Multianual y Gestión de Inversiones, una Unidad Productora "es el conjunto de recursos o factores productivos (infraestructura, equipos, personal, organización, capacidades de gestión, entre otros) que, articulados entre sí, tienen la capacidad para proveer bienes o servicios a la población objetivo. Constituye el producto generado o modificado por un proyecto de inversión".

En la tipología de proyectos de inversión en ecosistemas, se considera como Unidad Productora al ecosistema; sus factores de producción son agua, suelo, cobertura vegetal, especies, clima, gestión del ecosistema, los cuales, de manera articulada y funcional, generan la capacidad para proveer de servicios ecosistémicos a la población.

Dependiendo del tipo de ecosistema, habrá factores que son esenciales para el buen funcionamiento del ecosistema. Por ejemplo, en un bosque relicto son factores esenciales el suelo y el agua; mientras que en un bofedal es esencial la cobertura vegetal, que dependerá del agua y del suelo. 


\section{Marco normativo}

En relación con ecosistemas y servicios ecosistémicos

- Ley n. ${ }^{\circ}$ 26821, Ley Orgánica para el Aprovechamiento Sostenible de los Recursos Naturales.

- Ley n. ${ }^{\circ} 26834$, Ley de Áreas Naturales Protegidas y su Reglamento aprobado por Decreto Supremo N. ${ }^{\circ}$ 038-2001-AG.

- Ley . $^{\circ}$ 26839, Ley sobre la conservación y aprovechamiento sostenible de la diversidad biológica y su Reglamento aprobado con Decreto Supremo N. ${ }^{\circ}$ 0682001-PCM.

- Ley . $^{\circ} 28216$, Ley de protección al acceso a la diversidad biológica peruana y los conocimientos colectivos de los pueblos indígenas.

- Ley n. ${ }^{\circ} 28245$, Ley Marco del Sistema Nacional de Gestión Ambiental.

- Ley n. ${ }^{\circ} 28611$, Ley General del Ambiente.

- Decreto Supremo n. ${ }^{\circ}$ 012-2009-MINAM, que aprueba la Política Nacional del Ambiente.

- Decreto Supremo n. 016-2009-MINAM, que aprueba el Plan Director de las Áreas Naturales Protegidas.

- Decreto Supremo n. ${ }^{\circ}$ 014-2011- MINAM, que aprueba el Plan Nacional de Acción Ambiental - PLANAA 2011-2021.

- Decreto Supremo n. ${ }^{\circ}$ 009-2014-MINAM, que aprueba la Estrategia Nacional de Diversidad Biológica al 2021 y su Plan de Acción 2014-2018.

- Ley n. ${ }^{\circ}$ 30215, Ley de Mecanismos de Retribución por servicios ecosistémicos, 2014.

- Sistema Nacional de Programación Multianual y Gestión de Inversiones

- Decreto Legislativo n. ${ }^{\circ} 1252$, que crea el Sistema Nacional de Programación Multianual y Gestión de Inversiones y sus modificatorias.

- Decreto Supremo N ${ }^{\circ} 284-2018-E F$, que aprueba el Reglamento del Decreto Legislativo n. ${ }^{\circ} 1252$.

- Resolución Directoral n. ${ }^{\circ}$ 001-2019-EF/63-.01, que aprueba la Directiva General del Sistema Nacional de Programación Multianual y Gestión de Inversiones.

Propuesta de intervenciones mediante infraestructura natural con fines de mitigación de riesgos de inundación y movimientos de masa

Para la identificación de intervenciones se considera, entre otros dispositivos legales, el Decreto Supremo No 017-2018-MINAM que aprueba los lineamientos para la incorporación sobre infraestructura natural y gestión de riesgos en un contexto de cambio climático, en el marco de la reconstrucción con cambios.

\section{Identificación de activos generados con inversiones}

La propuesta de activos estratégicos se basa en los resultados de la revisión de los estudios de preinversión de proyectos en la tipología de ecosistemas (bien y servicio) que fueron declarados viables entre 2015 - 2018, así como aquellos que se han considerado para su financiamiento por el MERESE. 
Entre los activos generados con dichas intervenciones se han encontrado los siguientes:

- Superficie reforestada o superficie revegetada.

- Zanjas de infiltración.

- Terrazas de formación lenta, para la retención de suelos.

- Diques para el control de cárcavas.

- Diques, reservorios, Qochas, para retención de agua.

- Cercos de exclusión.

- Cercos perimétricos.

- Barreras vivas cortavientos o protección ecosistema.

- Muros de contención.

- Sistemas de riego para áreas reforestadas o revegetadas.

- Canales de conducción de agua en amunas.

De acuerdo con la muestra, el 97,6 \% de los proyectos consideran intervenciones de reforestación y revegetación, el 59,5 \% zanjas de infiltración, un 14,3 \% diversos mecanismos de protección del ecosistema.

De acuerdo con el documento Plan de Gestión de Riesgo y Adaptación al Cambio Climático en el Sector Agrario, Período 2012-2021 (PLANGRACC-A). En el Perú, las actividades en la atención, prevención y reducción de riesgo de desastres han sido principalmente orientadas a la población urbana en temas de vivienda, agua, saneamiento, salud e infraestructura. Sin embargo, los desastres en la agricultura y medios de vida de las poblaciones rurales han impactado económica y socialmente sin que se haya hecho mucho por reducir el impacto de los eventos climáticos extremos sobre la actividad agrícola a un nivel local y regional. Esto nos lleva a destacar la necesidad de adaptación, generación de resiliencia y reducción de vulnerabilidad ya que se pone en riesgo la seguridad alimentaria del país. Por ello, es prioridad para el Ministerio de Agricultura, el desarrollo de un plan de gestión del riesgo y adaptación al cambio climático en su sector.

\section{Eje estratégico 3}

Prevención y reducción de riesgos considerando eventos climáticos

- Objetivo Específico 3.1. Infraestructura hidráulica construida adecuadamente para la prevención y reducción de riesgos por inundación y sequía en zonas agrícolas vulnerables.

- Objetivo Específico 3.2. Identificación, uso y conservación adecuada de las variedades nativas y crianzas con técnicas agroecológicas para la reducción del impacto de eventos climáticos.

- Objetivo Específico 3.3 Manejo de Pastos, Suelos y Aguas mejorado para la reducción de riesgos en la agricultura

- Objetivo Específico 3.4. Prácticas de forestación/reforestación, agroforestería y manejo de bosques adecuados para reducir el impacto de eventos climáticos extremos. 


\section{Tabla 2}

\section{Rol de organismos e instituciones en Gestión de Riesgos del sector agrarios}

\begin{tabular}{|c|c|c|}
\hline Organismo & Capacidades & Rol en el PLANGRACC \\
\hline $\begin{array}{l}\text { Dirección General de } \\
\text { Asuntos Ambientales } \\
\text { Agrarios (DGAAA) }\end{array}$ & $\begin{array}{l}\text { Cuenta con un presupuesto de } 2 \text { millones } \\
\text { de soles del } 2012 \text { al } 2016 \text { para el } \\
\text { monitoreo del PLANGRACC-A. }\end{array}$ & $\begin{array}{l}\text { Asesoramiento normativo } \\
\text { para los ejes } 3 \text { y } 5 \text {. Tema: } \\
\text { Suelos y Monitoreo del } \\
\text { PLANGRACC-A. }\end{array}$ \\
\hline $\begin{array}{l}\text { Dirección General de } \\
\text { Infraestructura } \\
\text { Hidráulica (DGIH) }\end{array}$ & $\begin{array}{l}\text { Desde el año } 2009 \text { cuenta con un } \\
\text { Programa de protección de valles y } \\
\text { poblaciones rurales vulnerables ante } \\
\text { inundaciones, que contribuirá al } \\
\text { subprograma de defensas ribereñas, así } \\
\text { como un programa de almacenamiento y } \\
\text { regulación de lagunas con fines agrícolas } \\
\text { por S/ } 405 \text { millones, que contribuirá al } \\
\text { subprograma de construcción de } \\
\text { reservorios. }\end{array}$ & $\begin{array}{l}\text { Asesoramiento normativo } \\
\text { en el eje } 3\end{array}$ \\
\hline Dirección General de & Cuenta con 22 Administraciones Técnicas & $\begin{array}{l}\text { Asesoramiento Técnico- } \\
\text { Normativo en el eje 3, } \\
\text { pudiendo asesorar a los }\end{array}$ \\
\hline $\begin{array}{l}\text { Flora y Fauna Silvestre } \\
\text { (DGFFS) }\end{array}$ & $\begin{array}{l}\text { Forestales y de Fauna Silvestre (ATFFS), a } \\
\text { nivel nacional. }\end{array}$ & $\begin{array}{l}\text { gobiernos regionales en } \\
\text { temas forestales, y en } \\
\text { canalizar fondos externos } \\
\text { en temas forestales. }\end{array}$ \\
\hline $\begin{array}{l}\text { Oficina de Estudios } \\
\text { Económicos y } \\
\text { Estadísticos (OEEE) }\end{array}$ & $\begin{array}{l}\text { La Oficina de Estudios Económicos y } \\
\text { Estadísticos cuenta con técnicos } \\
\text { agropecuarios y personal para la } \\
\text { realización de encuestas, asimismo, } \\
\text { recopila y maneja datos } \\
\text { hidrometeorológicos. }\end{array}$ & $\begin{array}{l}\text { Asesoramiento normativo } \\
\text { a los ejes 1, 2, } 3 \text { y } 4 \text {. }\end{array}$ \\
\hline $\begin{array}{l}\text { Oficina de Planeamiento } \\
\text { y Presupuesto (OPP) }\end{array}$ & $\begin{array}{l}\text { La oficina de planeamiento y presupuesto } \\
\text { cuenta con una oficina a nivel central } \\
\text { para realizar el seguimiento y evaluación } \\
\text { del sector público agrario. }\end{array}$ & $\begin{array}{l}\text { Asesoramiento normativo y } \\
\text { de monitoreo en el eje } \\
\text { estratégico 5: Puede realizar } \\
\text { acciones de monitoreo del } \\
\text { PLANGRACC-Ay apoyar } \\
\text { financieramente para } \\
\text { proyectos seleccionados a } \\
\text { nivel central e institucional } \\
\text { en el marco del } \\
\text { PLANGRACC. }\end{array}$ \\
\hline \multicolumn{3}{|l|}{ PROYECTOS ADSCRITOS } \\
\hline $\begin{array}{l}\text { Programa de Desarrollo } \\
\text { Productivo Agrario Rural } \\
\text { (AGRORURAL) }\end{array}$ & $\begin{array}{l}\text { Tiene una oficina central y } 200 \text { sedes y } \\
\text { subsedes ubicadas en } 20 \text { regionales } \\
\text { del Perú. Tiene un presupuesto de } 111 \\
\text { millones con todos sus programas. } \\
\text { Cuenta con aproximadamente } 1,000 \\
\text { personas. }\end{array}$ & $\begin{array}{l}\text { Operador de proyectos, } \\
\text { pudiendo ejecutar acciones } \\
\text { de asesoramiento técnico y } \\
\text { ejecución en el eje } 3 \text { en } \\
\text { temas de desarrollo rural, } \\
\text { manejo de cuencas y } \\
\text { cambio climático, en el eje } 4 \\
\text { con asistencia técnica para } \\
\text { el manejo de cuencas, y en } \\
\text { el eje } 5 \text { con el apoyo a la } \\
\text { capacitación técnica. }\end{array}$ \\
\hline
\end{tabular}




\begin{tabular}{|c|c|c|}
\hline Organismo & Capacidades & Rol en el PLANGRACC \\
\hline $\begin{array}{l}\text { Proyecto Sub- sectorial } \\
\text { de irrigación (PSI) }\end{array}$ & $\begin{array}{l}\text { El proyecto sub-sectorial de irrigación } \\
\text { cuenta con un presupuesto de S/91 } \\
\text { millones, donde el 70\% es financiamiento } \\
\text { exterior y } 3130 \% \text { recursos del tesoro } \\
\text { público, operando desde el año } 2011 \text { en } \\
\text { Sierra. }\end{array}$ & $\begin{array}{l}\text { Asesor técnico de proyectos } \\
\text { en el eje 3, acción } \\
\text { estratégica de manejo de } \\
\text { agua para reducir el riesgo a } \\
\text { la sequía e inundaciones en } \\
\text { la agricultura, así como en la } \\
\text { acción estratégica de } \\
\text { construcción de reservorios, } \\
\text { puede apoyar técnicamente } \\
\text { a las regiones }\end{array}$ \\
\hline $\begin{array}{l}\text { Programa de } \\
\text { Compensaciones para la } \\
\text { Competitividad } \\
\text { (AGROIDEAS) }\end{array}$ & $\begin{array}{l}\text { El porcentaje de cofinanciamiento por } \\
\text { parte del programa varía entre } 60 \% \text { y } \\
80 \% \text {, según la magnitud de recursos que } \\
\text { le son solicitados, pudiéndose solicitar } \\
\text { hasta por un máximo de S/.1'080,000. } \\
\text { Apoya directamente a Gobiernos } \\
\text { Regionales. }\end{array}$ & $\begin{array}{l}\text { Financiador. Apoyo en } \\
\text { el eje 1. Puede contribuir } \\
\text { otorgando créditos a los } \\
\text { productores que planteen } \\
\text { innovación agraria } \\
\text { sostenible. }\end{array}$ \\
\hline \multicolumn{3}{|c|}{ ORGANISMOS PUBLICOS ADSCRITOS (OPA) } \\
\hline $\begin{array}{l}\text { Instituto Nacional de } \\
\text { Innovación Agraria (INIA) }\end{array}$ & $\begin{array}{l}\text { El INIA cuenta con } 13 \text { estaciones } \\
\text { experimentales a nivel nacional, y } 70 \\
\text { puntos de atención distribuidos a lo largo } \\
\text { de todo el territorio nacional, lo que le } \\
\text { posibilita tener una cobertura nacional. } \\
\text { Tiene un programa de cultivos andinos, } \\
\text { una Dirección de Recursos Genéticos, } \\
\text { además de ser la Autoridad Nacional en } \\
\text { semillas. El presupuesto se ha reducido } \\
\text { en un } 37 \% \text { en los últimos } 4 \text { años. Debe } \\
\text { ser fortalecido a nivel nacional. }\end{array}$ & $\begin{array}{l}\text { Asesoramiento técnico en } \\
\text { los ejes } 1,3 \text { y } 5 \text {, pudiendo } \\
\text { contribuir a través de sus } 12 \\
\text { estaciones. }\end{array}$ \\
\hline $\begin{array}{l}\text { Autoridad Nacional del } \\
\text { Agua (ANA) }\end{array}$ & $\begin{array}{l}\text { El ANA cuenta con Autoridades Locales } \\
\text { de Agua a nivel nacional y Autoridades } \\
\text { Autónomas del Agua. }\end{array}$ & $\begin{array}{l}\text { Asesoramiento normativo } \\
\text { en los ejes } 1,3 \text { y } 4 .\end{array}$ \\
\hline $\begin{array}{l}\text { Servicio Nacional de } \\
\text { Sanidad Agraria (SENASA) }\end{array}$ & $\begin{array}{l}\text { EI SENASA, mantiene un sistema de } \\
\text { Vigilancia Fitosanitaria y Zoosanitaria, que } \\
\text { protegen al país del ingreso de plagas y } \\
\text { enfermedades que no se encuentran en } \\
\text { el Perú y es el Ente responsable de } \\
\text { cautelar la seguridad sanitaria del agro } \\
\text { nacional. }\end{array}$ & $\begin{array}{l}\text { Asesoramiento técnico - } \\
\text { normativo en el eje } 2 \text { : puede } \\
\text { apoyar en la prevención, } \\
\text { control y erradicación de } \\
\text { plagas y enfermedades que } \\
\text { se han incrementado por } \\
\text { efecto del cambio climático, } \\
\text { fortaleciendo el sistema } \\
\text { sanitario nacional. }\end{array}$ \\
\hline
\end{tabular}

Nota: MINAGRI.2012. Plan Nacional de Gestión de Riesgo y Adaptación al Cambio Climático en el Sector Agrario, período 2012 - 2021 (PLANGRACC-A)"

De acuerdo con el Decreto Supremo Nº17-2018_MINAM. Lineamientos Para La Incorporación De Criterios Sobre Infraestructura Natural Y Gestión Del Riesgo En Un Contexto De Cambio Climático, En El Marco De La Reconstrucción Con Cambios. Considera la identificación e implementación de medidas de Infraestructura Natural se considera de manera referencial, para la reducción del riesgo de desastres. Estas medidas podrán ser, entre otras:

- Reforestación con especies nativas

- Revegetación con especies nativas 
- Diques para control de cárcavas

- Instalación de terrazas de formación lenta

- Enriquecimiento del suelo

- Construcción de zanjas de infiltración

- Construcción de Qochas o Cochas

- Barreras rompe vientos

Tabla 3

Caracterización de las intervenciones en ecosistemas

\begin{tabular}{|c|c|c|c|c|}
\hline $\begin{array}{c}\text { Tipo de } \\
\text { intervención }\end{array}$ & Descripción & Objetivos & $\begin{array}{c}\text { Medidas } \\
\text { complementarias }\end{array}$ & Indicadores \\
\hline $\begin{array}{l}\text { Reforestación } \\
\text { con especies } \\
\text { nativas }\end{array}$ & $\begin{array}{l}\text { Repoblar zonas con } \\
\text { plantaciones de árboles } \\
\text { y/o arbustos en un } \\
\text { espacio natural que en el } \\
\text { pasado estaba cubierto } \\
\text { de bosques que se ha } \\
\text { perdido o alterado. }\end{array}$ & $\begin{array}{l}\text { Reducir la erosión } \\
\text { hídrica del suelo. } \\
\text { Mejorar la } \\
\text { regulación hídrica. }\end{array}$ & $\begin{array}{l}\text { Zanjas de } \\
\text { infiltración. } \\
\text { Terrazas de } \\
\text { formación lenta. } \\
\text { Revegetación. } \\
\text { Enriquecimiento } \\
\text { del suelo. }\end{array}$ & $\begin{array}{l}\text { Superficie } \\
\text { reforestada. } \\
\text { Hectáreas } \\
\text { (ha). }\end{array}$ \\
\hline $\begin{array}{l}\text { Diques para } \\
\text { control de } \\
\text { cárcavas }\end{array}$ & $\begin{array}{l}\text { Construcción de muros } \\
\text { (de troncos, palos o } \\
\text { piedras) ubicados } \\
\text { perpendicularmente y en } \\
\text { forma de media luna a la } \\
\text { cárcava. Las dimensiones } \\
\text { y las distancias entre los } \\
\text { diques dependen de la } \\
\text { profundidad y pendientes } \\
\text { de la cárcava }\end{array}$ & $\begin{array}{l}\text { Reducir la erosión } \\
\text { hídrica del suelo. } \\
\text { Mejorar la } \\
\text { regulación hídrica. } \\
\text { Estabilización de } \\
\text { taludes. }\end{array}$ & $\begin{array}{l}\text { Reforestación y } \\
\text { Forestación. } \\
\text { Revegetación con } \\
\text { pastos naturales. }\end{array}$ & $\begin{array}{l}\text { Diques } \\
\text { instalados. } \\
\text { Número. } \\
\text { Superficie de } \\
\text { erosión } \\
\text { controlada. } \\
\text { Hectáreas } \\
\text { (ha). }\end{array}$ \\
\hline $\begin{array}{l}\text { Instalación } \\
\text { de terrazas } \\
\text { de formación } \\
\text { lenta y } \\
\text { recuperación } \\
\text { de andenes }\end{array}$ & $\begin{array}{l}\text { Son franjas secuenciales } \\
\text { que dividen la ladera en } \\
\text { secciones } \\
\text { perpendiculares a la } \\
\text { pendiente, protegidos por } \\
\text { muros de piedra o de } \\
\text { tierra. Las terrazas son } \\
\text { formadas } \\
\text { progresivamente por } \\
\text { efecto de acumulación de } \\
\text { sedimentos. }\end{array}$ & $\begin{array}{l}\text { Controlar el } \\
\text { proceso erosivo } \\
\text { del suelo e } \\
\text { incrementar la } \\
\text { infiltración del } \\
\text { agua en el suelo }\end{array}$ & $\begin{array}{l}\text { Reforestación. } \\
\text { Revegetación. }\end{array}$ & $\begin{array}{l}\text { Longitud de } \\
\text { franjas } \\
\text { instaladas. } \\
\text { Metros } \\
\text { lineales (m) } \\
\text { Superficie con } \\
\text { terrazas } \\
\text { formadas. } \\
\text { Hectáreas } \\
\text { (ha). }\end{array}$ \\
\hline $\begin{array}{l}\text { Construcción } \\
\text { de zanjas de } \\
\text { infiltración }\end{array}$ & $\begin{array}{l}\text { Son excavaciones que se } \\
\text { realizan en laderas en } \\
\text { forma de canales de } \\
\text { sección rectangular o } \\
\text { trapezoidal, que se } \\
\text { construyen a curvas de } \\
\text { nivel para detener la } \\
\text { escorrentía del agua de } \\
\text { lluvias y almacenarlas. }\end{array}$ & $\begin{array}{l}\text { Interceptar y } \\
\text { almacenar la } \\
\text { escorrentía } \\
\text { superficial del } \\
\text { agua de lluvias. } \\
\text { Reducir la erosión } \\
\text { hídrica del suelo. }\end{array}$ & $\begin{array}{l}\text { Reforestación. } \\
\text { Revegetación }\end{array}$ & $\begin{array}{l}\text { Longitud de } \\
\text { zanjas. Metros } \\
\text { lineales (m). } \\
\text { Superficie de } \\
\text { terrenos con } \\
\text { zanjas } \\
\text { construidas. } \\
\text { Hectáreas } \\
\text { (ha). }\end{array}$ \\
\hline
\end{tabular}

Fuente: Adaptado de catálogo de medidas de recuperación y conservación de infraestructura natural. MINAM 2018. Catálogo de obras y prácticas de conservación de suelos y agua. SAGARPA MÉXICO. 


\section{Servicios Ecosistémicos}

Son aquellos beneficios económicos, sociales y ambientales, directos e indirectos, que las personas obtienen del buen funcionamiento de los ecosistemas y se agrupan en cuatro tipos:

a) Servicios de Provisión: Estos beneficios son los que se obtienen de los bienes y servicios que las personas reciben directamente de los ecosistemas, entre ellos tenemos: alimentos, agua fresca, materias primas, recursos genéticos, entre otros.

b) Servicios de Regulación: Estos beneficios se obtienen a través de la regulación de los procesos de los ecosistemas, tales como: regulación de calidad del aire, regulación del clima, control de la erosión de suelo, regulación de riesgos naturales, secuestro de carbono, entre otros. Los beneficios de estos servicios para las personas se dan de manera indirecta.

c) Servicios Culturales: Son los beneficios no materiales que las personas obtienen de los ecosistemas. Entre ellos tenemos la belleza paisajística, la recreación y el ecoturismo, la inspiración para la cultura, el arte y el diseño, la experiencia espiritual y la información para el desarrollo del conocimiento.

d) Servicios de Soporte: Agrupa los servicios necesarios para producir los otros servicios ecosistémicos como: ciclo de nutrientes, formación de suelos, producción primaria y mantenimiento de la biodiversidad (especies, genes y ecosistemas).

La siguiente tabla explica las tipologías de servicios ecosistémicos, el servicio de regulación incluye el servicio de regulación de riesgos naturales que aplica para la mitigación de riesgos de inundación y movimientos de masa.

Tabla 4

Servicios ecosistémicos por tipologías

\begin{tabular}{ll}
\hline \multicolumn{1}{c}{ Tipos de servicios } & \multicolumn{1}{c}{ Servicios ecosistémicos } \\
\hline & Regulación de la calidad de aire \\
& Regulación del clima \\
& Regulación de riesgos naturales \\
Servicio de regulación & Regulación hídrica \\
& Control de la erosión de suelo \\
& Purificación del agua y tratamiento de aguas de desecho \\
& Secuestro de carbono ${ }^{2}$ \\
\cline { 2 - 3 } Servicios culturales & Valores culturales y religiosos \\
& Valores estéticos \\
& Belleza paisajística \\
& Recreación y ecoturismo
\end{tabular}

\footnotetext{
2 En el caso de proyectos cuyos beneficios estén asociados a la reducción o mitigación de las emisiones de gases de efecto invernadero, se utilizarán los parámetros de evaluación establecidos en el Anexo N. 3 de la Directiva N. ${ }^{\circ}$ 02-2017-EF/63.01 con relación a la Tasa social de descuento y precio social del carbono.
} 


\begin{tabular}{cl}
\hline Tipos de servicios & \multicolumn{1}{c}{ Servicios ecosistémicos } \\
\hline \multirow{3}{*}{ Servicios de soporte } & Ciclo de Nutrientes \\
& $\begin{array}{l}\text { Formación de suelos } \\
\text { Producción primaria } \\
\\
\end{array}$ \\
& Mantenimiento de la biodiversidad (especies, genes y ecosistemas) \\
\hline
\end{tabular}

Los servicios ecosistémicos de regulación hídrica y control de la erosión de suelo se abordan en la tipología de proyectos Ecosistema, a través de intervenciones en los servicios ecosistémicos. Asimismo, los servicios ecosistémicos de belleza escénica o paisajística se abordan en la tipología de proyectos Apoyo al uso sostenible de la biodiversidad, a través de intervenciones en el ecosistema.

Los proyectos de inversión en las tipologías de ecosistemas y especies (ambos a través de intervenciones en el bien) permitirán de manera indirecta la recuperación de los otros servicios ecosistémicos, constituyéndose en beneficios de dichos proyectos (por ejemplo: polinización, secuestro de carbono, entre otros), los cuales podrán ser susceptibles de ser valorados.

- Servicio ecosistémico de regulación hídrica: Este servicio se origina cuando el ecosistema almacena agua en los periodos lluviosos y la libera lentamente en los periodos secos. Es decir, el ecosistema proporciona un balance natural entre caudales en época lluviosa con caudales de estiaje. A mayor capacidad de regulación, se espera un incremento del caudal base y una reducción en época de avenidas.

La regulación hídrica depende principalmente de la intensidad y la estacionalidad de las precipitaciones, la cobertura vegetal, la profundidad del suelo, la alteración de la variabilidad climática y las prácticas de conservación de agua.

- Servicio ecosistémico de regulación de control de erosión de suelo: Es la capacidad del ecosistema de disminuir las fuerzas que provocan el desprendimiento de las partículas de suelo, principalmente las fuerzas de erosión producidas por el agua. La cobertura vegetal evita la exposición del suelo a la acción de la lluvia, la escorrentía y el viento, impidiendo la erosión.

- Servicio ecosistémico cultural de belleza paisajística: Es la capacidad del ecosistema conservado en brindar el disfrute a la vista o el oído del patrimonio natural.

\section{Objetivo general}

Desarrollo de un Sistema de Información Geográfica-SIG para aplicaciones forestales, que permita caracterizar y zonificar áreas aptas para la reforestación y a su vez fortalezca la capacidad técnica de la región para implementar estos procesos técnicos en sus programas de desarrollo forestal.

\section{Objetivos específicos}

- Desarrollar una aplicación Sistema de Información Geográfica-SIG, en ambiente ARCGIS 10.6.1 para usos forestales en las cuencas ubicadas en el área de 
influencia de la cuenca de tal forma que permita seleccionar áreas aptas para intervenciones de infraestructura natural con el objetivo de mitigar riesgos de inundación y movimientos de masa mediante la reforestación y a su vez, fortalezca la capacidad técnica de las instituciones y organismos públicos y privados regionales para implementar programas de desarrollo forestal para mitigar riesgos mediante la recuperación de servicios ecosistémicos.

- Identificar zonas potenciales para plantaciones forestales en la cuenca del río Rímac que cumplan con el objetivo de mitigar inundaciones y movimientos de masa mediante el control de erosión hídrica del suelo y fomentando la infiltración de agua principalmente para regulación hídrica.

\section{MATERIALES Y MÉTODOS}

En la actualidad se están utilizando como información primaria los Sistemas de Información Geográfica (SIG), ya que ellos nos entregan información base fundamental al momento de poder evaluar alternativas en la utilización de los espacios. Junto con ello, la información técnica digitalizada que agrupa gran cantidad de datos, además de imágenes satelitales y la ayuda en terreno de los Sistemas de Posicionamiento Global (GPS).

En el presente estudio se evalúa los factores que influyen de manera directa en la obtención de intervenciones y áreas óptimas con el objetivo de mitigación de riesgos de inundación y movimientos de masa en la cuenca Rímac, mediante Técnicas de Evaluación Multicriterio y Sistemas de Información Geográfica (SIG)

Con la información obtenida mediante el Modelo de Capacidad de Acogida y utilizando como base principal datos oficiales del INGEMMT, IGN, INEI, SENAMHI, ANA, SERFOR, MINAM, MINAGRI, MTC, INDECI, GEOCATMIN, WorldClim GlobalClimate Data.

Tabla 5

Datos de entrada para el geoprocesamiento

\begin{tabular}{|c|c|c|c|c|}
\hline ítem & Fuentes & Ponderación & Descripción & Ponderación \\
\hline $\begin{array}{c}\text { Precipitación } \\
\text { total anual }\end{array}$ & $\begin{array}{l}\text { Mapa de } \\
\text { isoyetas }\end{array}$ & $\begin{array}{l}1=<350 \mathrm{~mm} \\
2=350-600 \\
3=>600\end{array}$ & $\begin{array}{l}\text { La disponibilidad hídrica es factor } \\
\text { decisivo en éxito de plantaciones. } \\
\text { Las zonas con precipitación } \\
\text { mayor a } 500 \text { se consideran } \\
\text { óptimas. }\end{array}$ & 20 \\
\hline Altitud & Dem & $\begin{array}{l}1>4000 \\
2 \text { de } 3500-4000 \\
32500-3500\end{array}$ & $\begin{array}{l}\text { Las especies requieren } \\
\text { condiciones de altitud adecuadas }\end{array}$ & 15 \\
\hline Vigor vegetación & $\begin{array}{l}\text { NDVI mes de } \\
\text { junio y octubre }\end{array}$ & $\begin{array}{l}1=>0-0.1 \mathrm{Sin} \\
\text { vegetación } \\
2=0.1-0.2 \text { Vigor } \\
\text { medio, vegetación } \\
\text { ligera y media } \\
3=>0.2 \text { vigor alto, } \\
\text { vegetación alta }\end{array}$ & $\begin{array}{l}\text { Asegura crecimiento de } \\
\text { plantación al ser zonas con } \\
\text { vegetación vigorosa y un valor de } \\
\text { NDVI mayor a } 0.2\end{array}$ & 15 \\
\hline
\end{tabular}




\begin{tabular}{|c|c|c|c|c|}
\hline ítem & Fuentes & Ponderación & Descripción & Ponderación \\
\hline $\begin{array}{l}\text { Susceptibilidad } \\
\text { mm }\end{array}$ & $\begin{array}{c}\text { Mapa de } \\
\text { susceptibilidad } \\
\text { de } \\
\text { movimientos } \\
\text { de masa } \\
\text { MINAM }\end{array}$ & $\begin{array}{l}1=\text { BAJO } \\
2=\text { MEDIO } \\
3=A L T O\end{array}$ & $\begin{array}{l}\text { Se prioriza las áreas con mayor } \\
\text { susceptibilidad }\end{array}$ & 15 \\
\hline Topografía & $\begin{array}{l}\text { Pendiente en } \\
\text { grados }\end{array}$ & $\begin{array}{l}1=0-30^{\circ} \\
2=30-45 \\
3=>45\end{array}$ & $\begin{array}{l}\text { La pendiente es un principal } \\
\text { factor de susceptibilidad de } \\
\text { movimientos de masa, las } \\
\text { pendientes óptimas están entre } \\
\text { los } 30^{\circ} \text { a más. }\end{array}$ & 15 \\
\hline $\begin{array}{l}\text { Centros } \\
\text { Poblados } \\
\text { distancia }\end{array}$ & $\begin{array}{l}\text { Centros } \\
\text { Poblados } \\
\text { MINEDU }\end{array}$ & $\begin{array}{l}\text { valor } 1>5000 \mathrm{~m} \\
\text { valor } 2 \text { de } 3000-5000 \\
m \\
\text { valor } 3 \text { de } 0-3000 \mathrm{~m}\end{array}$ & $\begin{array}{l}\text { Los valores más cercanos son los } \\
\text { óptimos el valor } 3 \text { indica que las } \\
\text { áreas óptimas están de o a 3,000 } \\
\text { metros. }\end{array}$ & 10 \\
\hline $\begin{array}{l}\text { Cobertura } \\
\text { vegetal }\end{array}$ & $\begin{array}{c}\text { Mapa de } \\
\text { cobertura } \\
\text { vegetal MINAM } \\
2015\end{array}$ & $\begin{array}{l}1=\text { Agricultura } \\
2=\text { Pajonal } \\
3=\text { Matorral arbustivo, } \\
\text { bosque relicto }\end{array}$ & $\begin{array}{l}\text { La vegetación es un indicativo } \\
\text { para acciones de forestación y } \\
\text { reforestación }\end{array}$ & 10 \\
\hline \multirow[t]{2}{*}{ Fallas geológicas } & GEOCATMIN & $\begin{array}{l}\text { valor } 1>3000 \mathrm{~m} \\
\text { valor } 2=2000-3000 \mathrm{~m} \\
\text { valor } 3=\text { de } 0-2,000 \mathrm{~m}\end{array}$ & $\begin{array}{l}\text { Los valores más cercanos son los } \\
\text { óptimos el valor } 3 \text { indica que las } \\
\text { áreas óptimas están de o a 3,000 } \\
\text { metros. }\end{array}$ & 10 \\
\hline & & & Total & 100 \\
\hline
\end{tabular}

\section{RESULTADOS}

A continuación, se definen las matrices que fueron evaluadas por los expertos, donde se obtuvo la asignación de cada juicio de valor, incluyendo la razón de consistencia obtenida.

Tabla 6

Matriz madre de la evaluación realizada con sus respectivos juicios de valor asignados

\begin{tabular}{lcc}
\hline \multicolumn{1}{c}{ Datos de entrada } & Ponderación & Ubicación del mapa \\
\hline Precipitación total anual & 10 & Figura 1 \\
Peligros geológicos & 7 & Figura 2 \\
Movimientos de masa & 10 & Figura 3 \\
Vigor de vegetación & 10 & Figura 4 \\
Pendiente & 10 & Figura 5 \\
Accesibilidad y vías de comunicación & 10 & Figura 6 \\
Altitudes para reforestación & 10 & Figura 7 \\
Cobertura vegetal & 5 & Figura 8 \\
Fallas & 5 & Figura 10 \\
TOTAL & 100 & \\
\hline
\end{tabular}

La ponderación está formada por un rango del 1 al 3, se considera la óptima la ponderación 3. 
Figura 1

Mapa de precipitación total anual

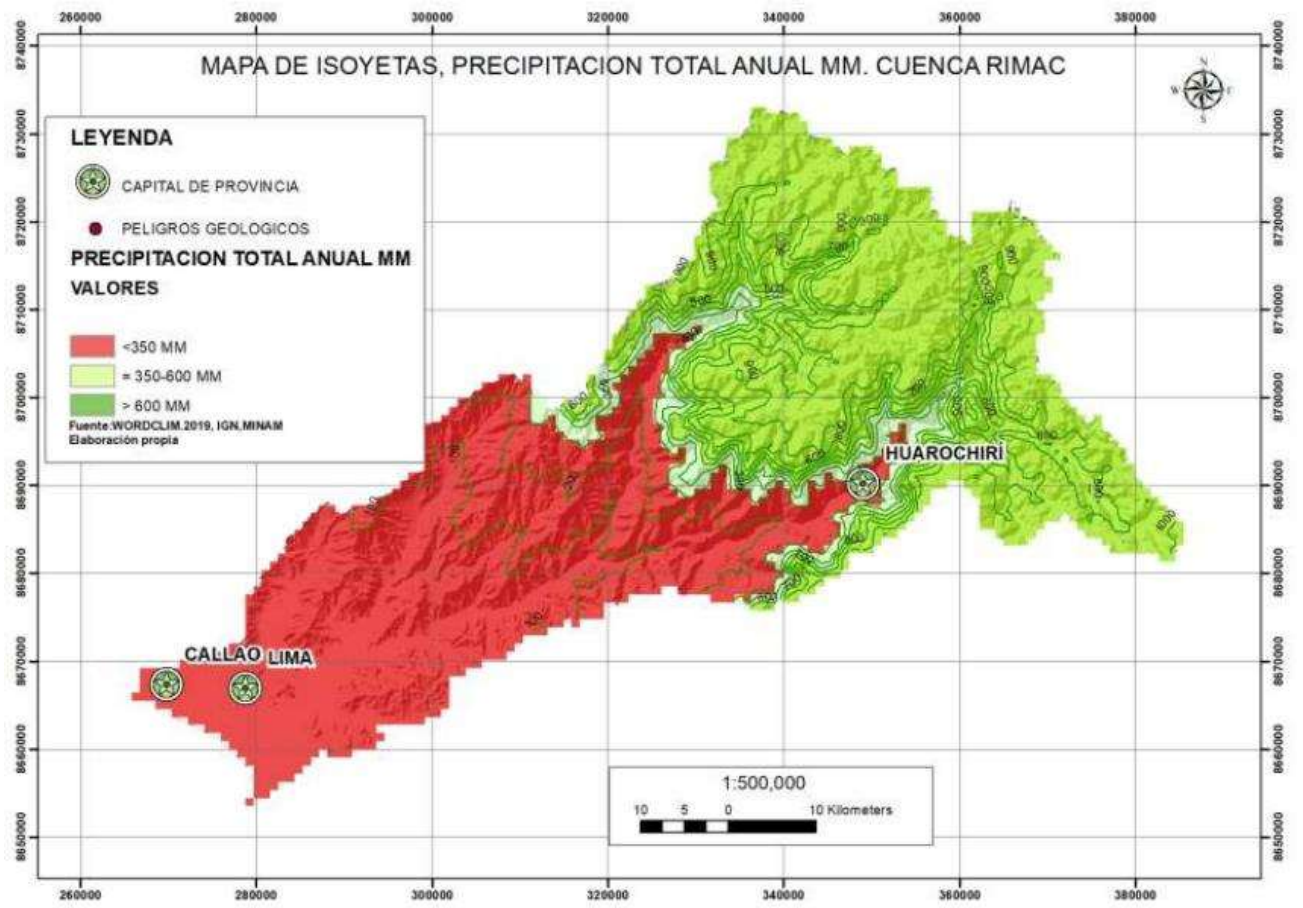

Figura 2

Mapa de peligros geológicos de la cuenca del río Rímac

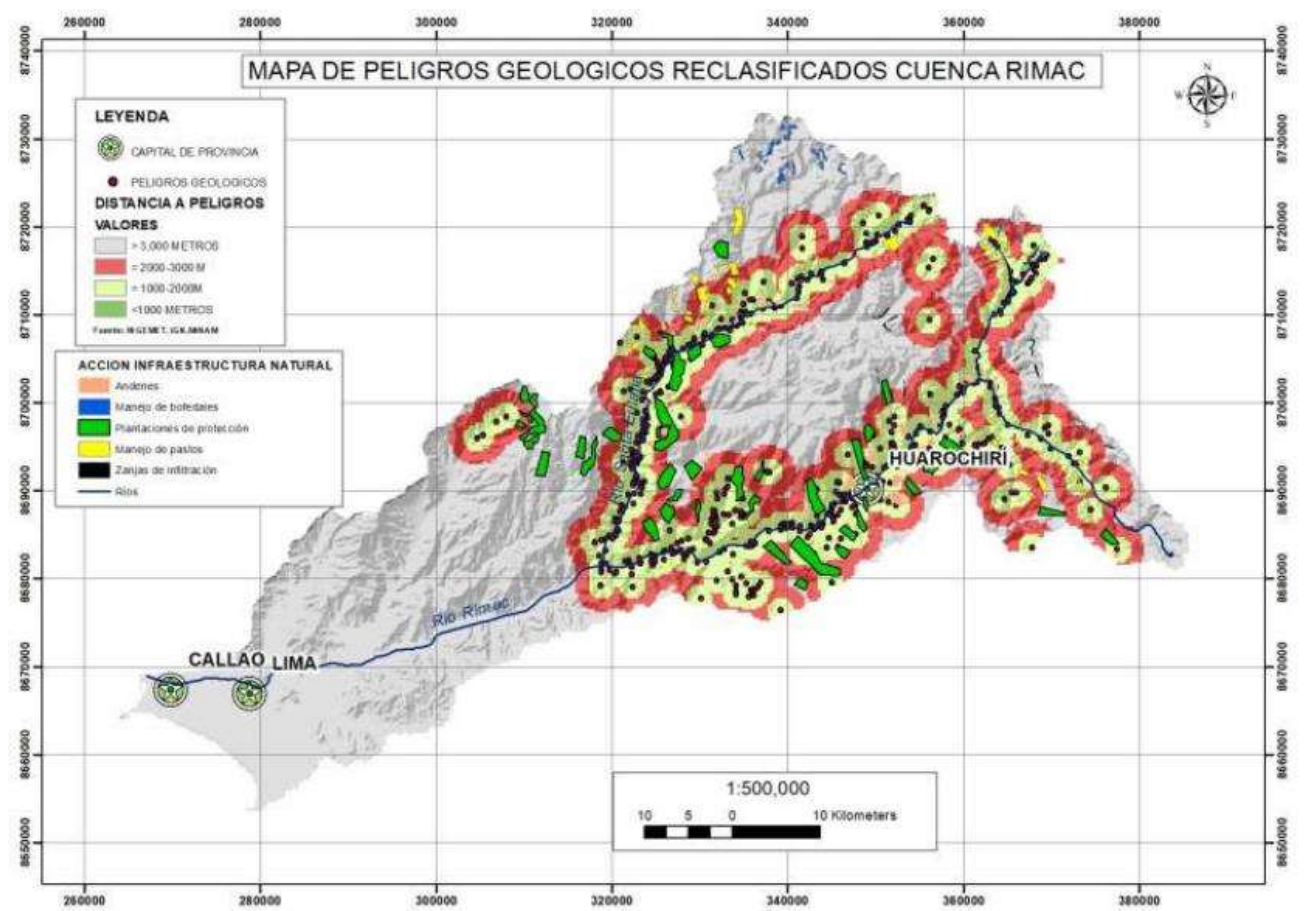


Figura 3

Mapa de susceptibilidad a movimientos en masa de la cuenca del río Rímac

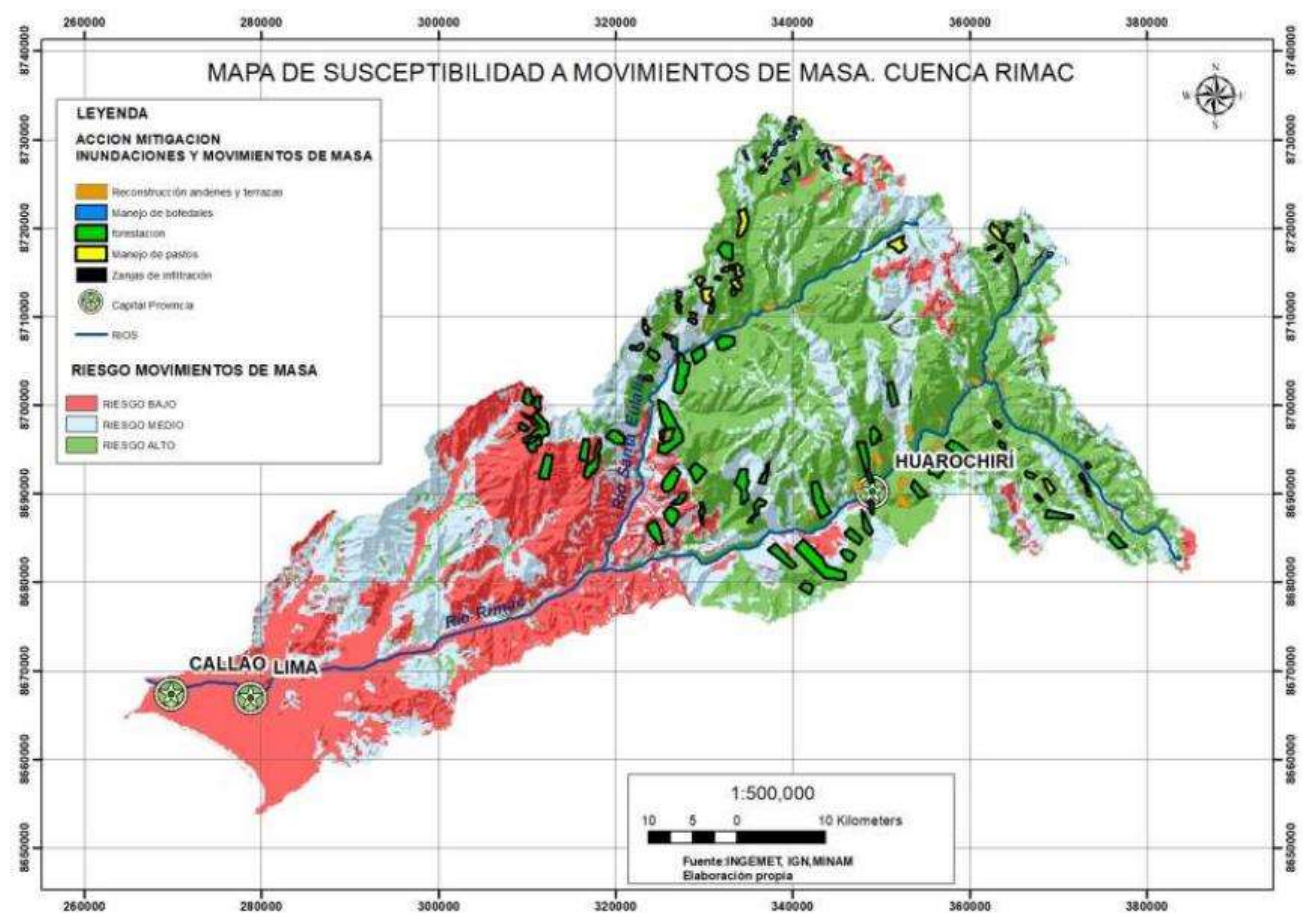

Figura 4

Mapa de vigor de la vegetación de la cuenca del río Rímac

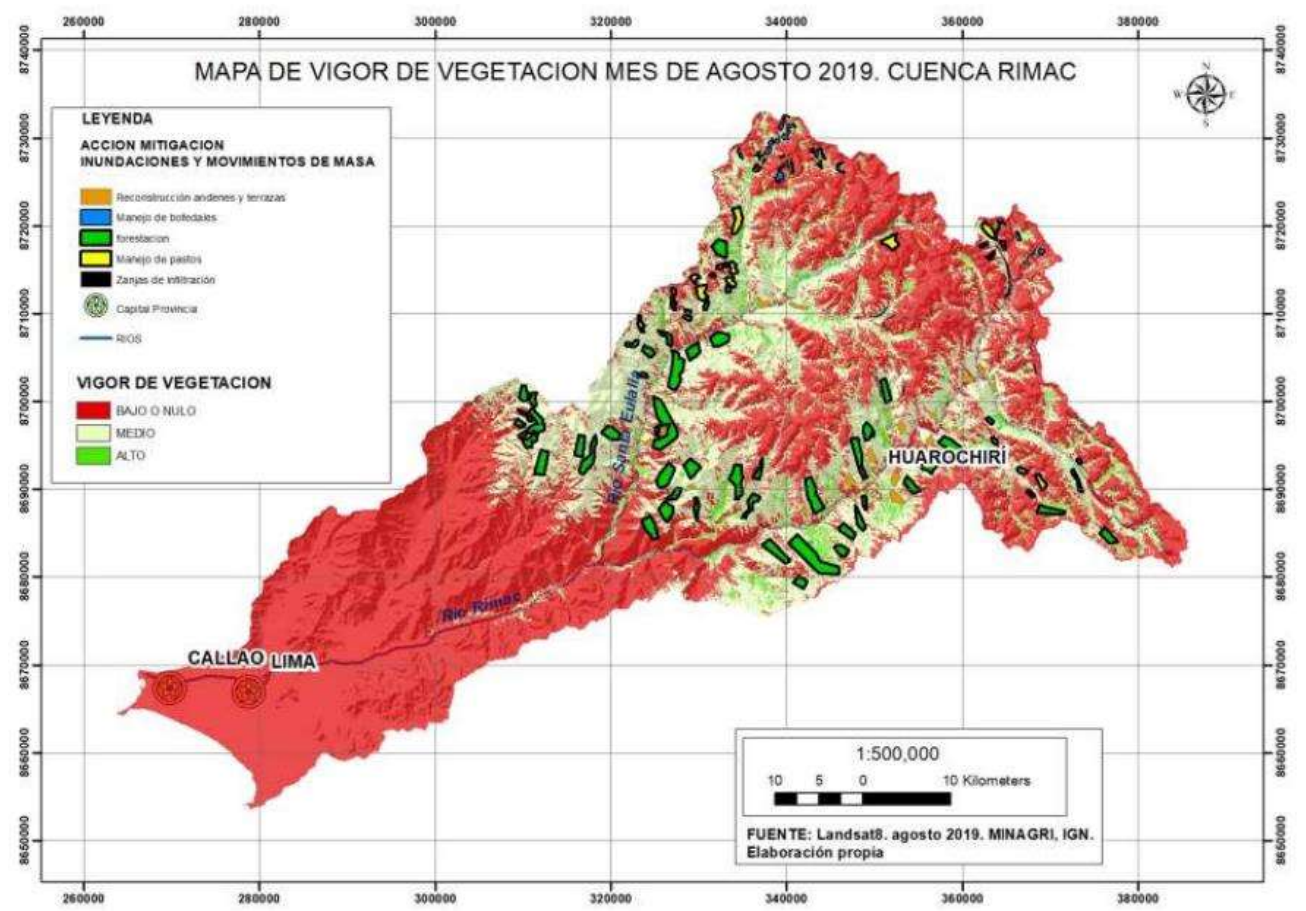


Figura 5

Mapa de pendientes de la cuenca del río Rímac

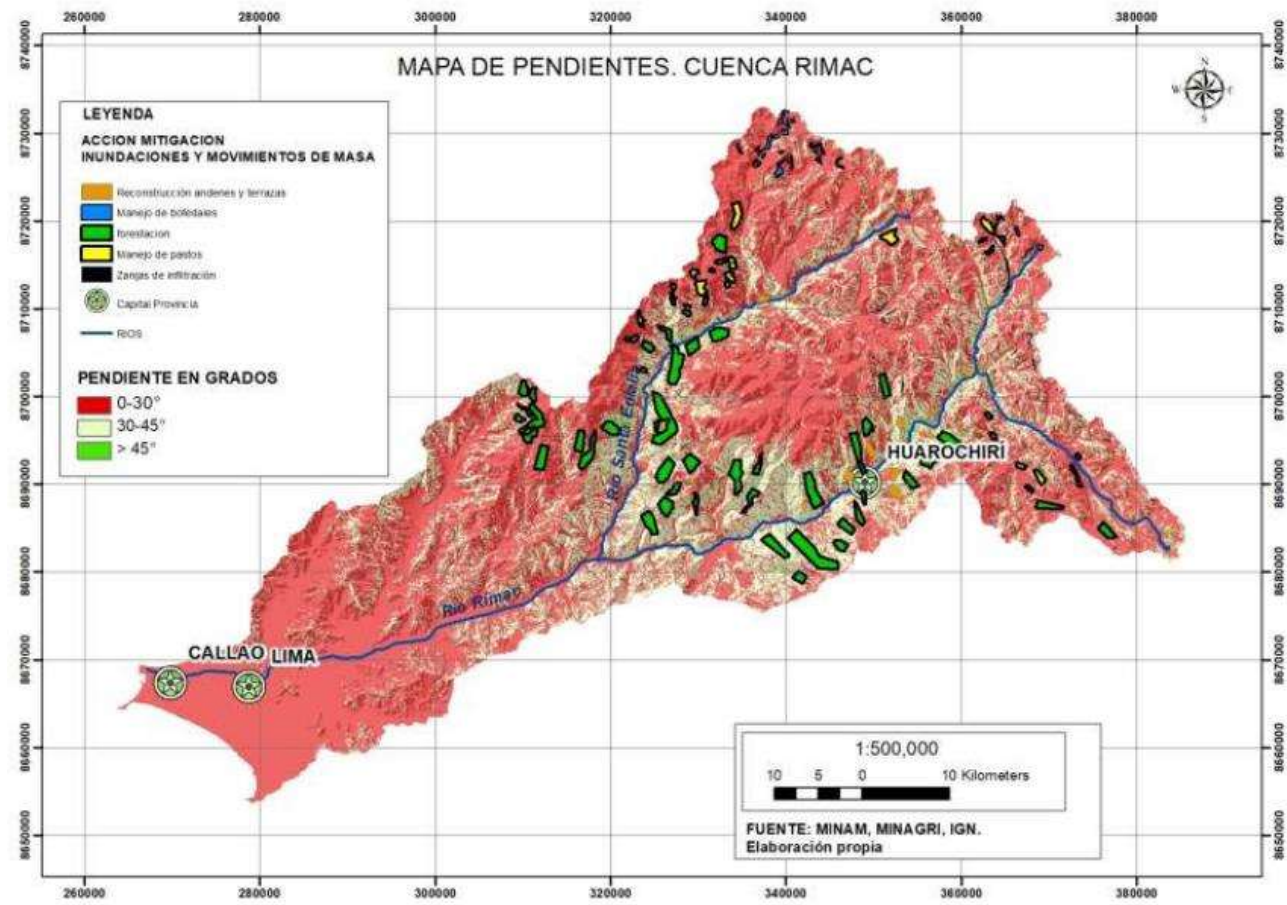

Figura 6

Mapa de accesibilidad de la cuenca del río Rímac

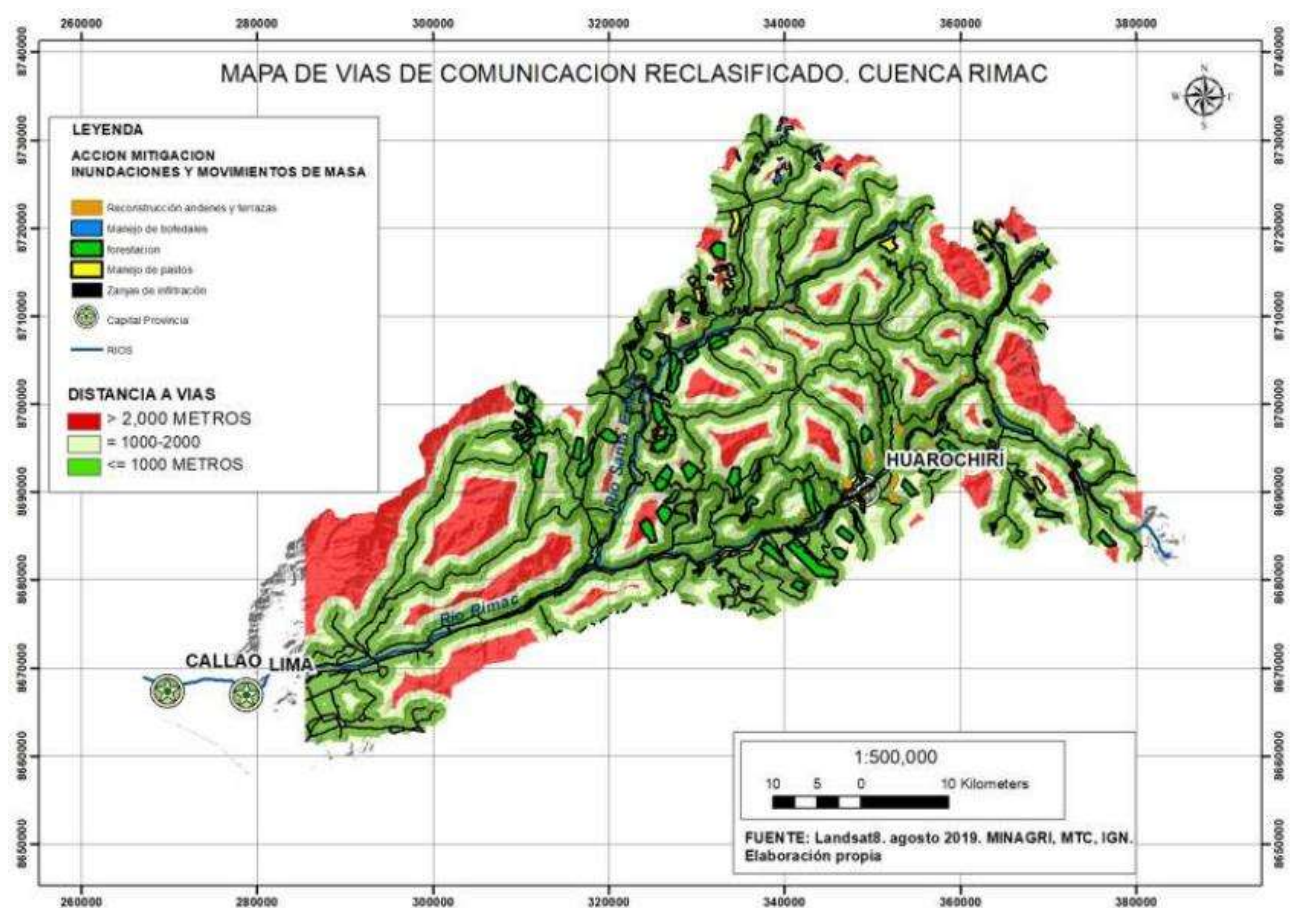


Figura 7

Mapa de altitudes de la cuenca del río Rímac

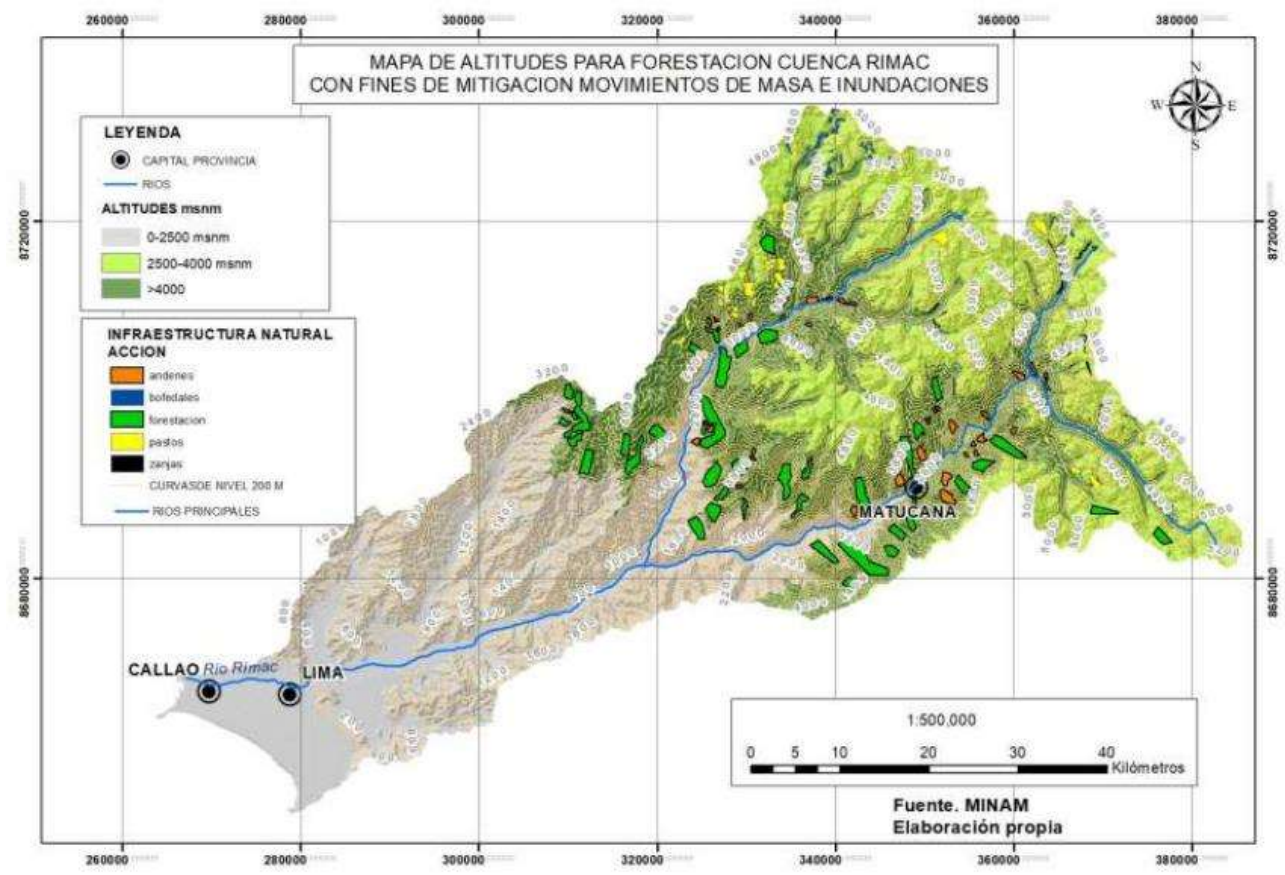

Figura 8

Mapa de cobertura vegetal de la cuenca del río Rímac

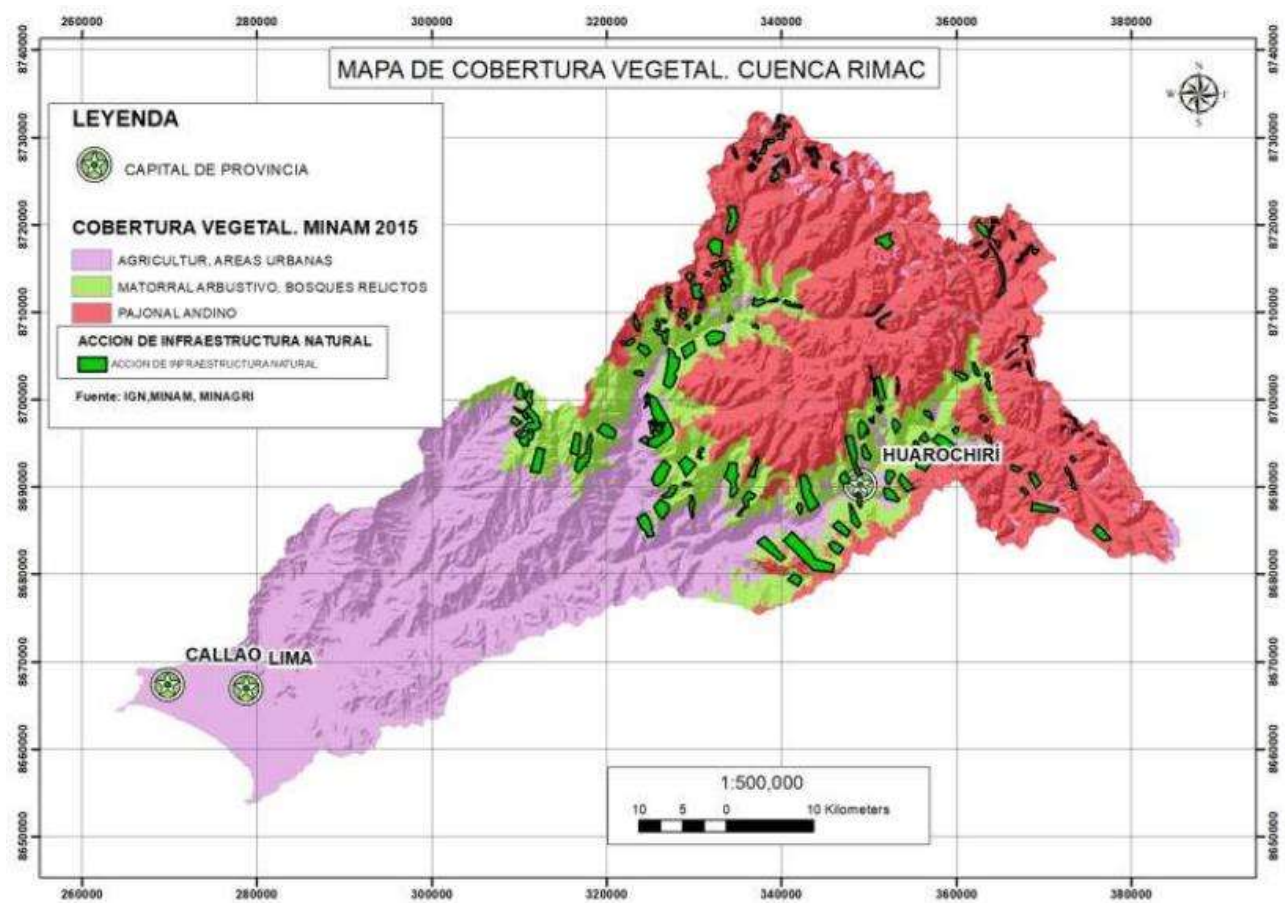


Figura 9

Mapa de microcuencas de la cuenca del río Rímac

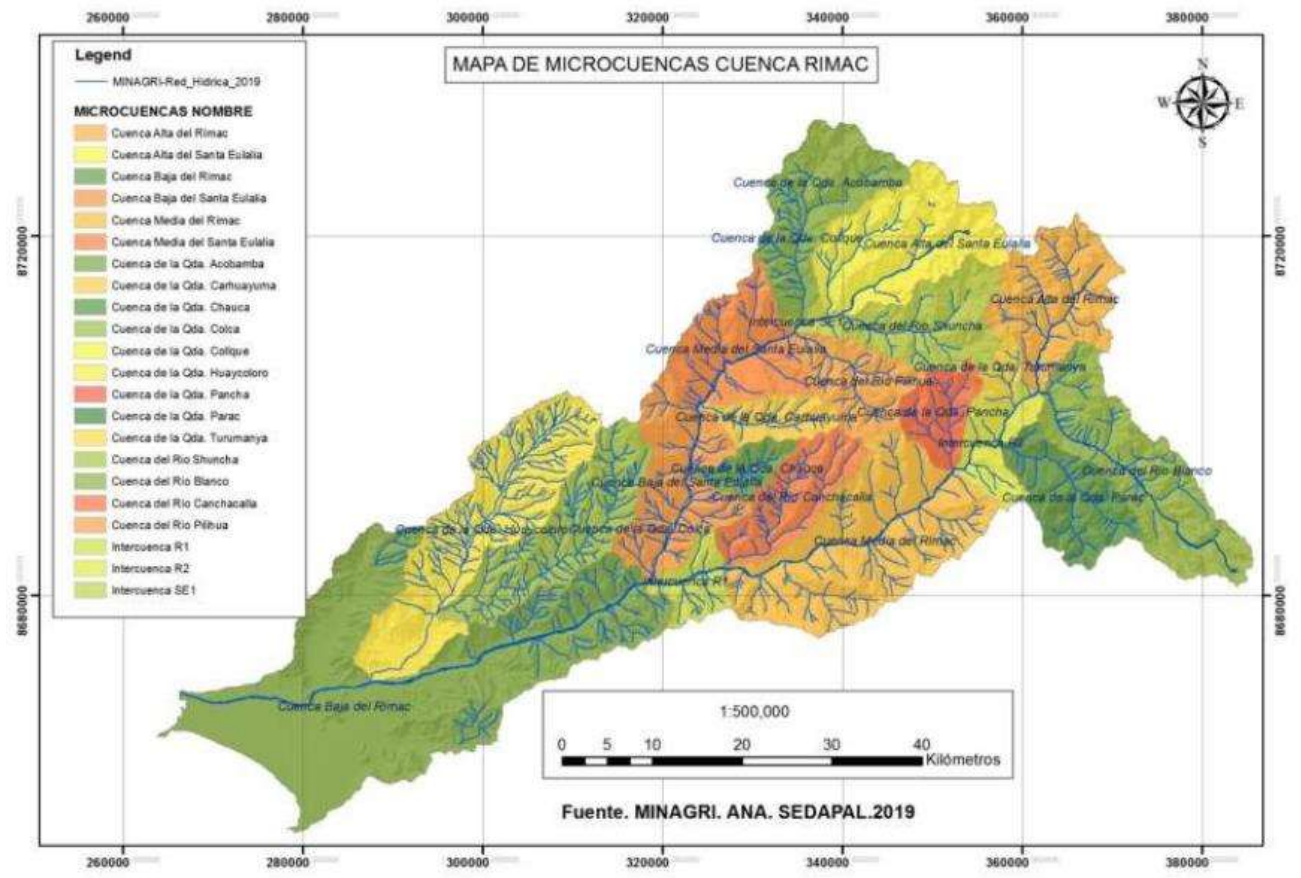

Figura 10

Mapa de fallas geológicas de la cuenca del río Rímac

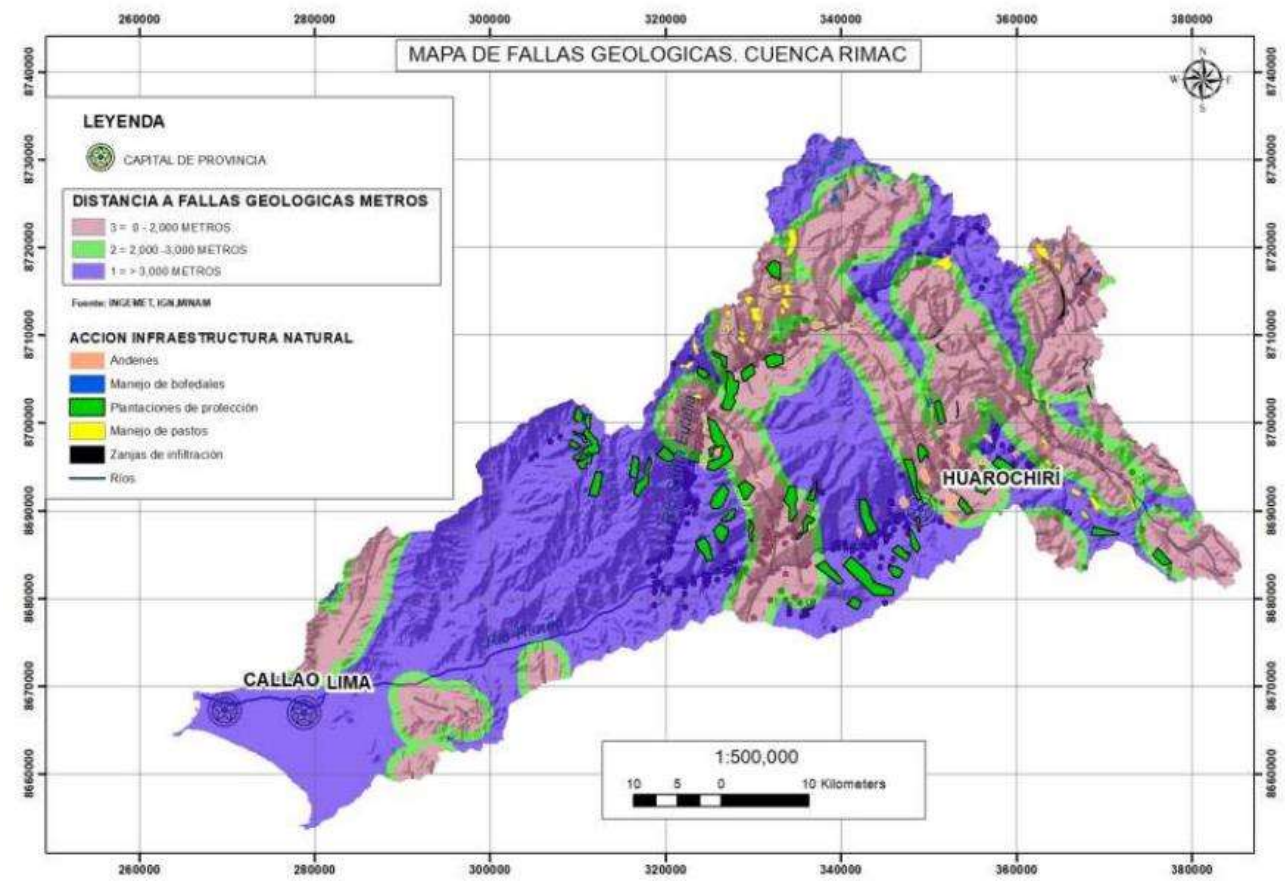


Figura 11

Mapa de intervenciones de infraestructura natural por comunidad campesina

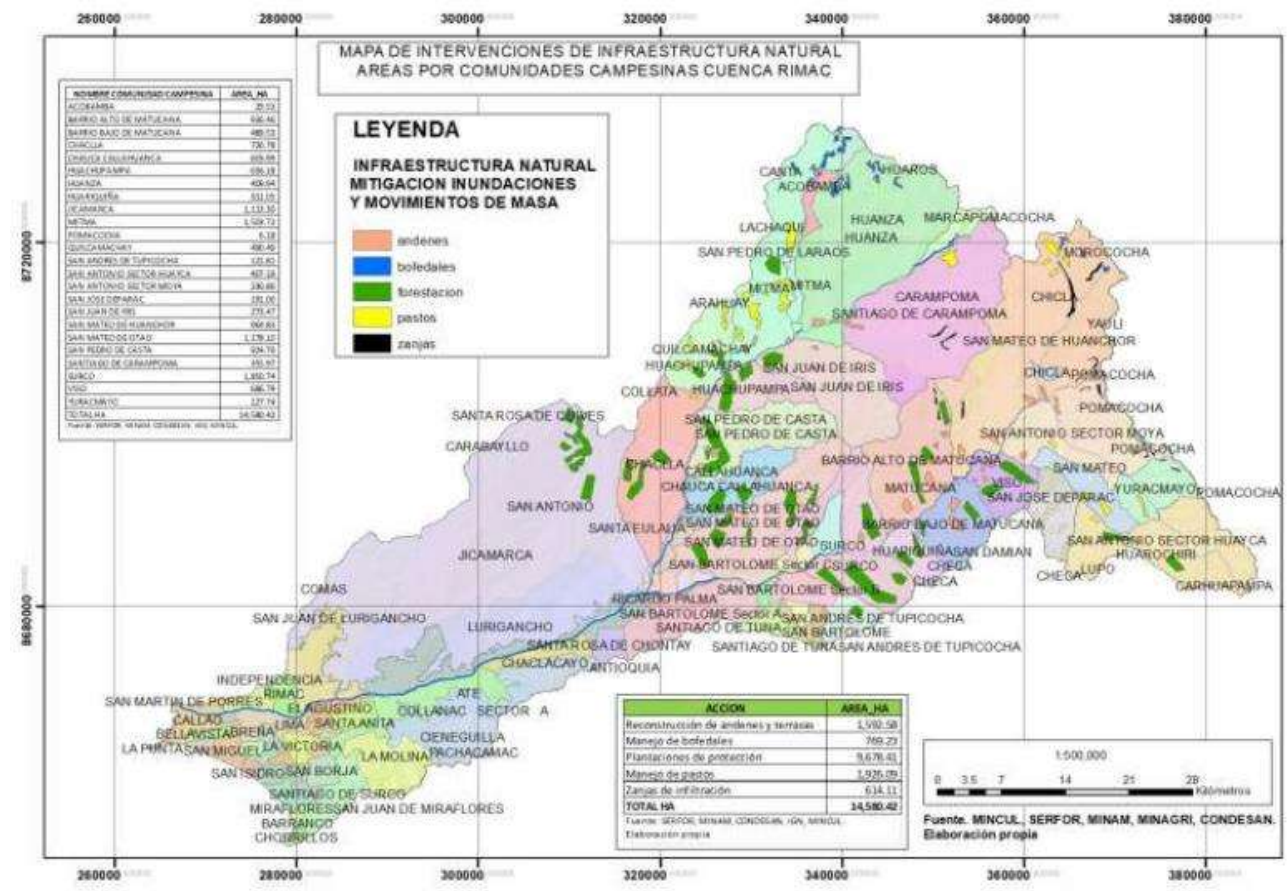

Figura 12

Mapa de intervenciones de infraestructura natural por distrito

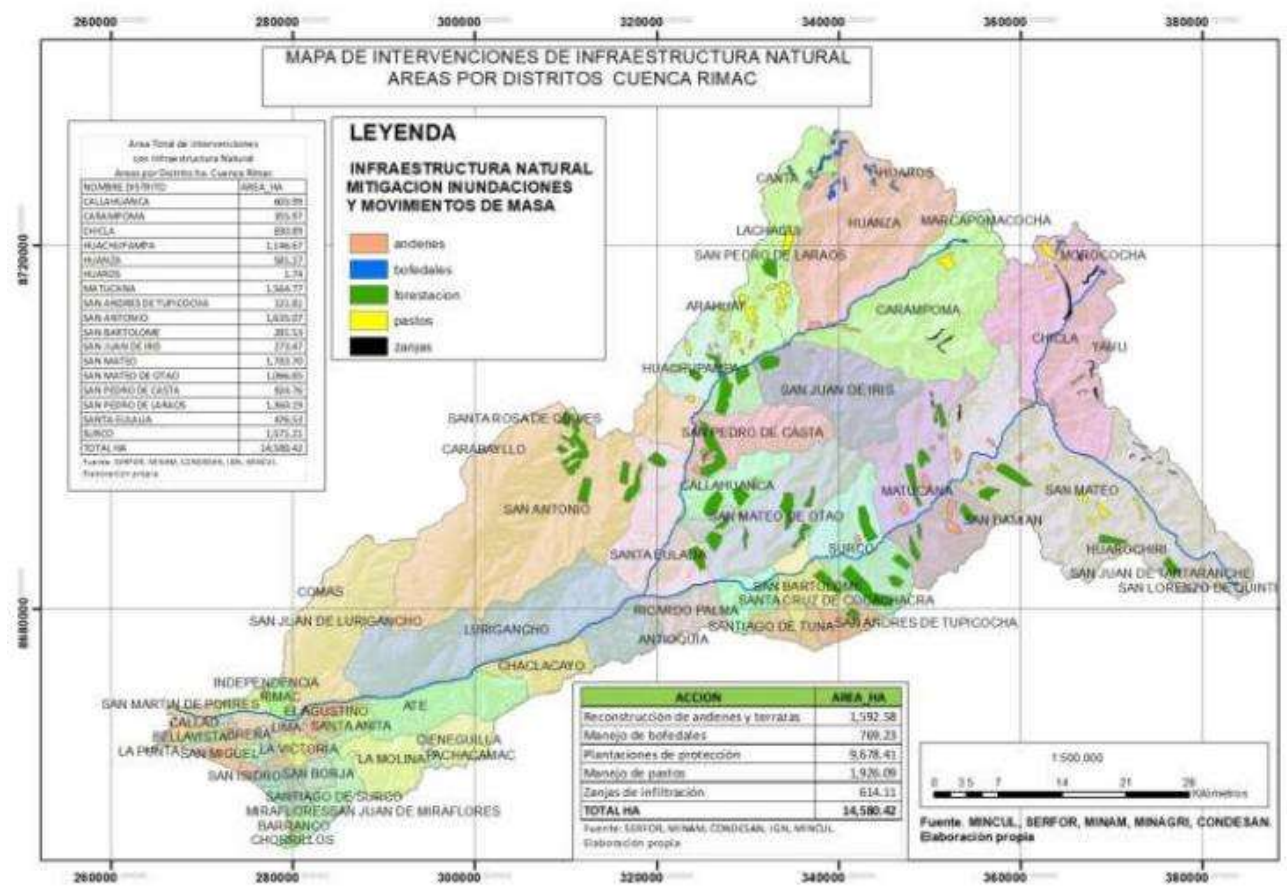




\section{CONCLUSIONES}

El área con aptitud alta para intervenciones con infraestructura natural para mitigar riesgos de inundación y movimientos de masa es la siguiente:

\section{Tabla 7}

Intervenciones Infraestructura Natural con fines de mitigación de riesgos de inundación y movimientos de masa. Cuenca Rímac

\begin{tabular}{lc}
\hline \multicolumn{1}{c}{ Acción } & Área (ha) \\
\hline Reconstrucción de andenes y terrazas & $1,592.58$ \\
Manejo de bofedales & 769.23 \\
Plantaciones de protección & $9,678.41$ \\
Manejo de pastos & $1,926.09$ \\
Zanjas de infiltración & 614.11 \\
Total (ha) & $14,580.42$ \\
\hline
\end{tabular}

\section{RECOMENDACIONES}

Se recomienda promover trabajos coordinados entre las distintas autoridades de la cuenca del río Rímac, que permitan implementar infraestructura natural basada en la reconstrucción de andenes, manejo de bofedales, plantaciones de protección, manejo de pastos y zanjas de infiltración.

Se recomienda involucrar a las empresas privadas las cuales tienen incidencia directa en la cuenca del Rímac, tales como mineras, empresas agrícolas entre otras a invertir en obras de infraestructura natural.

\section{REFERENCIAS}

Decreto Supremo N 017-2018_MINAM. Lineamientos Para La Incorporación De Criterios Sobre Infraestructura Natural Y Gestión Del Riesgo.

Guía Nacional de Valoración Económica del Patrimonio Natural, Ministerio del Ambiente (2015) y World Resources Institute (2003).

Ley 30215: Ley de Mecanismos de Retribución por Servicios Ecosistémicos

Ley 28611, Ley General del Ambiente; Ley 30215, Ley de Mecanismos de Retribución por Servicios Ecosistémicos,

MINAGRI.2012. Plan Nacional de Gestión de Riesgo y Adaptación al Cambio Climático en el Sector Agrario, período 2012 - 2021 (PLANGRACC-A)"

Resolución Ministerial N 440-2018-MINAM, publicada en el diario El Peruano el 21.12.2018.

Soto L., W.A., Cellen, R., De Bievere, Ver, Ochoa B. Borja, P (2012). Ecología, hidrología y suelos de páramos.

Suarez J. (2001). Control de erosión en zonas tropicales. BucaramangaColombia.556P 
Villanueva R. 2011; Los impactos del cambio climático en las funciones hidrológicas de la cuenca del rio Santa. 